\title{
Non-linearities in Specialization and Growth
}

\author{
Luca De Benedictis* Marco Gallegati ${ }^{\dagger}$ and Massimo Tamberi ${ }^{\ddagger}$
}

May 2003

\begin{abstract}
This paper investigates the link between overall specialization and growth, analyzing the shape of the relationship between the median of the sectoral distribution of the Balassa Index $(B I)$, our summary measure of overall specialization, and the level of per capita income.

We analyze the specialization pattern of different countries employing three nonparametric methods: Kernel smoothing, lowess, and rolling regressions procedures. The empirical evidence suggests a nonlinear relationship between countries' level of overall specialization and per capita income. We interpret such a non-linear relationship as the result of the different influence that the level of per capita income on one hand, and the existence of country-specific effects on the other, may have on sectoral diversification, according to the stage of development of a country.
\end{abstract}

DownLOADING: http://www.ssrn.com/abstract=412260.

Keywords: International Trade, Specialization, Revealed Comparative Advantages, Nonparametrics.

JEL Classification: C14, F10, F43, O57

*DIEF - University of Macerata - Italy. debene@unimc.it

${ }^{\dagger} \mathrm{DE}$ - University of Ancona - Italy. marcog@deanovell.unian.it

${ }^{\ddagger} \mathrm{DE}$ - University of Ancona - Italy. tamberi@deanovell.unian.it.

This is a preliminary draft, all comments are welcome. A first draft of the paper was presented at the CNR seminar on International Trade and Economic Development, Alghero - June 2002. We are very grateful to CNR for the financial support and to Lucia Tajoli for comments and encouragement. Errors and omissions are our own responsibility. 


\section{Contents}

1 Introduction 3

2 Trade, specialization and growth: three questions and two $\begin{array}{ll}\text { different perspectives. } & 4\end{array}$

3 Definition and object of the analysis $\quad 8$

4 Empirical evidence on specialization and per capita income 10

4.1 Description of the data set . . . . . . . . . . . . . . . 11

4.2 The median of $B I$ as a measure of specialization . . . . . . . . 11

4.3 The median of $B I$ and alternative measures of overall specialization .................... . . . 14

5 Nonparametric estimates $\quad \mathbf{1 6}$

5.1 Kernel smoothing and locally weighted polynomial regressions 16

5.2 Rolling regressions . . . . . . . . . . . . . . . . . . 21

6 Conclusions 23 
"... a country's economic growth may be defined as

a long-term rise in capacity to supply increasingly

diverse economic goods to its population."

Simon Kuznets, Nobel Prize Lecture, 1971.

\section{Introduction}

This paper investigates the link between overall specialization and economic growth.

While the latter term can be taken for granted, the former deserves some clarification. Even if the concept of specialization is one of the main pillars of economic theorizing, if one tries to bridge trade models with data inspection, the concept becomes more prone to semantic misinterpretation and frequent confusion. What does "specialization" mean? According to Ricardian trade theory, when a country opens up to trade it will specialize in line with comparative advantages, but this does not automatically imply that its overall degree of specialization will increase. The definition of specialization is in fact related to sectoral concentration in production and exports. ${ }^{1}$ In section 2 we will show how and when comparative advantages and specialization go together and when they go in opposite directions.

In order to place the discussion above on an empirical plane, one has to construct a measure of international specialization. Several measures have been proposed in the empirical literature; in this paper we built on De Benedictis and Tamberi (2002a), showing how the median of the sectoral empirical density function of the Balassa (1965) Index $(B I)$ of Revealed Comparative Advantage can be considered as a summary measure of overall specialization.

We will then derive the empirical relationship between specialization and per capita income using nonparametric regressions.

We should stress that our analysis of overall specialization does not have a direct implication either in terms of intra-distribution dynamics, nor in terms of the "quality" of specialization itself. Overall specialization tells us if a country produces many (few) goods, but does not say if those goods

\footnotetext{
${ }^{1}$ On one hand, production and exports should not be considered as perfect substitutes - both theoretically and empirically. On the other hand, the measure of specialization is strongly related to the very definition of sectors, and the measurement of overall specialization will therefore be influenced by the choice of sectoral aggregation of the dataset used.
} 
correspond to an optimal bundle (in terms of welfare, employment, growth, etc). Nonetheless, any proper analysis of the link between trade and growth should take the measure itself of overall specialization as its initial step.

The structure of the paper is as follows: section 2 schematizes the literature on trade, specialization and growth, and clarifies the nexus between comparative advantages and specialization; section 3 defines the object of the analysis; in section 4 the data utilized are first discussed, followed by the presentation of a comparison of different measures of overall international trade specialization, including our own proposal, the $B I$ median; section 5 introduces the econometric methodology used herein and presents the results on the relationship between specialization and per capita income; the last section is a conclusion.

\section{Trade, specialization and growth: three ques- tions and two different perspectives.}

This paper is related to two partially overlapping bodies of existing research that can be identified by two different, though interrelated, questions. They shall be introduced by a third and more fundamental question that we will answer immediately.

Question 0: What is specialization all about? International trade theory (Dixit and Norman, 1979; Krugman and Helpman, 1985) is the most natural place to look for possible answers. Let us start from the basics. When a (small) country opens up to trade it will take advantage of the opportunities associated with specialization and trade to separate production from consumption and to receive an overall net gain unfeasible under autarchy. That country will produce according to the international price signal. Does this imply an increase in overall specialization? Let us use a $2 \times 2 \times 2$ geometric example. Suppose that a country was producing at point $a^{t 1}$ under autarchy, as is shown in figure 1 , and the international price signal indicates $a^{u}$ as the production point - associated with the realization of comparative advantages - from which passes the dotted line indicating an equiproportional distribution of production shares (distribution is therefore uniform). The movement from $a^{t 1}$ towards $a^{u}$ indicates an increase in specialization in $\eta$ or, in other terms, a specialization of this country according to comparative advantages. However, at the same time the movement toward $a^{u}$ represents a decrease in overall specialization, since the country is now producing $\varpi$ and $\eta$ in the same proportion, while before it was producing relatively more $\varpi$ than $\eta$. Correspondence to comparative advantages does not automatically imply an 
increase in overall specialization, but only an increase in the relative production of $\eta$.

What about exports? Let us now suppose that the international price signal indicates $a^{t 0}$ as the production point of comparative advantages; the movement from $a^{t 1}$ towards $a^{t 0}$ passing through $a^{u}$ indicates an increase in specialization in $\eta$, a U-shaped path in overall specialization and a final result of no export specialization. Therefore, production specialization and export specialization should not be considered as equivalent.

[Figure 1 about here]

If the starting point was $a^{p}$ - corresponding to a protection of the national $\varpi$ sector through a tariff - and the international price signal indicated $a^{t 2}$ as the production point of comparative advantages, the country specialization shifts from $\varpi$ to $\eta$, showing a high degree of intra-distribution dynamics. Meanwhile, overall specialization would remain unchanged, and specialization measured in terms of trade flows would be reduced, since the area of the Meade-Harberger triangle shrinks, moving from $a^{p}$ to $a^{t 2}$.

In summary, we will call comparative advantages the correspondence to the international price signal and specialization the concentration of exports in one or a group of sectors.

Question 1: Is specialization changing over time? Let us start again from trade theory and, in particular, from its earlier dynamic extensions (Findlay, 1970; Deardorff, 1974; Eaton, 1987).

Let us imagine that our country has already manifested its comparative advantages according to the international price signal. If the signal is stable over time, comparative advantages would stand, and the country will always produce, sell and buy goods on the international market according to a changeless structure. Things vary in the presence of factor accumulation and the initial patterns of comparative advantages may be reinforced or weakened over time. Findlay-Schott's visual example is given (Findlay, 1970; Schott, 2001) in figure 2. In a simple multi-cone Heckscher-Ohlin model, a country such as the Philippines $(P)$ - which is relatively labor-abundant experiences a rapid rate of increase in its endowment of capital relative to labor. Its pattern of comparative advantages will change according to the sequence highlighted in figure 2 . At the start the Philippines was producing only good $Z$, while entering in the second cone it will produce $Z$ and $Y$, and while reaching the third cone abandon the $Z$ sector and produce $Y$ and $X$. Factor prices will change consistently and overall specialization - that was high at the very beginning - will initially drop and then rise again at a second stage; this will follow a U-shape pattern, as it was in figure 1 in the switch from $a^{t 1}$ to $a^{t 0}$, passing through $a^{u}$. 
In the case of Japan $(J)$, the process of capital accumulation will make the initial patterns of comparative advantages persist over time, and the degree of overall specialization will increase over time as well.

A more complex picture arises when not only endowment changes are taken into account. Redding (2001) built a theoretical model with an empirical slant: observed changes in specialization - measured in terms of sectoral shares of GDP - are explained by combinations of changes in factor endowments, technology and exogenous shocks that are common across countries but specific to individual industries. As in Proudman and Redding (1999), Brasili, Epifani and Helg (2000) and De Benedictis and Tamberi (2002a), changes in specialization are analyzed considering both the external shape of the distribution (the overall specialization) and the changes in the relative position of each sector (intra-distribution dynamics).

[Figure 2 about here]

A second line of literature emphasizes the role of non-diminishing returns to reproducible factors of production, endogenous technological change, $R \& D$ investment and learning by doing in causing a comparative advantages lockin (Lucas, 1988; Grossman and Helpman, 1991; Young, 1991). In this literature the presence of dynamic scale economies makes the long run trade pattern fully determined by initial endowments. In this case, only international spillovers and $\backslash$ or a difference in learning speed among sectors can modify the initial specialization pattern.

In summary, the answer to the first question is therefore yes: comparative advantage patterns do change over time if we observe an asymmetric factor accumulation and there is no lock-in due to learning by doing and dynamic economies of scale.

Question 2: Are specialization dynamics related to growth? Moving from price or endowment dynamics - the key elements in the answers to question 1 - to income and growth, there have not been many proponets of empirical solutions to this question. Weinhold and Rauch (1999), Bensidoun, Guillaume and Unal-Kesenci (2001) and Imbs and Wacziarg (2000) are the few exceptions. The latter is the piece of research most related to the present one, and which oriented our interest in the topic toward the use of nonparametric techniques. Imbs and Wacziarg (2000, p.1) assert that the field of specialization dynamics is related to development and, to be more precise, specialization "follows a U-shaped pattern in relation to per capita income". The non linear relation can be explained as follows. At early stages of development, countries are forced by circumstances to specialize in natural resources and struggle to diversify their production and exports, and 
climb the value added staircase. The necessity for countries to insure themselves against sectoral shocks and high trading costs, plus consumers' bias in favor of variety are two mutually reinforcing reasons for domestic diversification of production. If productivity rises, the spectrum of goods that a country produces with relative efficiency is enlarged and diversification in production and in exports increases. At this point international trade theory proposes the necessity of specialization. There are diverse reasons for this: comparative advantages, economies of scale, agglomeration advantages and pecuniary externalities. When countries develop and are able to compete on the international market with a range of different products, and transport costs fall due to the improvement of technology, the infrastructure, network building and international institutions, then they will have incentives to specialize. The same forces push toward the agglomeration of production and such geographic clustering translates into highly observed degrees of sectoral concentration and specialization (Imbs and Wacziarg, 2000, p.1). The authors test the proposition that the process of diversification-specialization, measured in terms of sectoral employment shares, follows a sequence of stages related to the level of development; thus evidence is found for a non-linear relation both within countries and across countries. Therefore, it can be concluded that since the level of yearly per capita income associated with the turning point of the U-shaped pattern is around $9000 \$$, countries diversify over most of their development path and only specialize at a mature stage of development.

Other authors - even if they were not directly exploring the relationship between specialization and economic growth - have investigated the evolution of specialization and contributed to the portfolio of possible answers. In particular Kim (1995), Amiti (1998), Brülhart (1999), De Benedictis and Tamberi (2001b) and Redding (2001), using different data sets and different analytical tools indirectly addressed the issue of specialization and growth; some of their conclusions can be sketched out for our purposes. Kim (1995) gives some evidence of what can be called an inverted U-shape relationship: analyzing the regions of the U.S. economy for about a century, he found that a significant part of US economic growth was characterized by a steady increase in regional specialization during the early stages of national growth. Subsequently, - from WWII onwards - a decrease in specialization was seen.

In De Benedictis and Tamberi (2002b) the general answer is once again yes, specialization is negatively related to the level of income per person, as the degree of mobility of the pattern of comparative advantages is also negatively related to development. In analyzing several OECD countries, Amiti (1998) found some evidence that countries progressively increase their overall degree of specialization: given the set of countries used, her analysis 
can be interpreted as support for the evidence of the second part of a Ushaped pattern. On the contrary, Redding (2001), still using a small sample of OECD countries, finds "no evidence of an increase in the extent to which countries' production is concentrated in a few industries" (p. 22).

The contribution of the present paper is to fully discuss the question under scrutiny and, more specifically, to provide some evidence of the possible nonlinearities in the relationship, and the shape of such non-linearities.

\section{Definition and object of the analysis}

Two fundamental issues should be clarified before starting the empirical analysis.

The first one has to do with the choice of the observational variable. Nowadays, it has become easy to find empirical trade analyses which use variables different from imports and exports to study specialization dynamics. Brülhart (1999) - among many potential examples - uses production, value added, employment and exports in order to analyze the changes in the respective specializations of European countries. What should be stressed is that such variables cannot be considered to be equivalent - as we have shown in the discussion of figure 1 - and the use of each different variable reveals the existence of different circumstances. The use of employment shares (Imbs and Wacziarg, 2000) implies that specialization is observed from the input viewpoint, the alternative of using production, whether value added or export, would imply that specialization is observed from the output viewpoint. Furthermore, the use of employment shares implies the assumptions of identical production functions across countries and sectors and the use of a shared common technology that must be justified; the resulting analysis shows a bias in favor of labor-intensive sectors that also needs to be justified. Finally, - keeping general equilibrium trade models in mind - it is obvious to think that trade specialization in different countries can have different effects on their production and employment structures depending on the different degree to which each economy is open.

The second issue is related to the use of long-run data and a fixed, predetermined (and not too finely distinguished) sectoral disaggregation, that could lead to the U-shaped pattern associated with the Philippines in figure 2. For example, take the typical aggregated data showing structural transformation in the long run: countries start as agricultural (concentration), and eventually arrive as tertiary (again concentration); somewhere in between there is a stage of diversification: some balanced shares of agriculture, industry, and services. Using Maddison's (1995) data on the U.S. employment 
shares of those three sectors in 1820,1913 , and $1992,{ }^{2}$ we can easily compute some naive evidence of a U-shaped pattern: the Herfindahl Index of concentration is in fact 0.54 in $1820 ; 0.35$ in 1913 ; 0.6 in 1992 . These data, not surprisingly, form a U-shaped pattern.

In short, the choice of aggregation level and the choice of time period length should be carefully inspected ${ }^{3}$ taking into account the following implications: (a) if growth happens through the increase in the variety of goods, an analysis with a fixed number of sectors does not really "capture" the spirit of the growth process; it can only measure a part of the structural change; (b) the previous implication is even more relevant if the analysis period is very long. This is due to the fact that even though the structural change is stronger in the long run, it is forced inside the cage of a fixed set of sectors, defined in some way; (c) finally, as a matter of fact, it is easy to compute examples in which different levels of disaggregation can involve different results in the dynamics of specialization; it would be possible to obtain an increasing degree of specialization with a low level of disaggregation (few sectors) and a decreasing one with a higher level of disaggregation (many sectors).

Following the above procedure, in using our data-set (described in section 4.1 ), we computed some measure of overall specialization both at the two and the four digit level. The result is that, depending on the chosen index, about $1 / 6$ of the countries has the two time paths going in opposite directions, and in these cases the index of linear correlation between the two has a negative sign and is not negligible in magnitude. ${ }^{4}$

Summarizing, with a fixed number of sectors the economy starts its development path specialized in the "old" sectors and finishes by being specialized in the "new" ones; in between there is a point at which both sectors are relevant and diversification occurs, but this is a matter of definition. Instead, as Simon Kuznets (1973, p.247) clearly pointed out, "a country's economic growth may be defined as a long-term rise in capacity to supply increasingly diverse economic goods to its population." Despite the above statement,

\footnotetext{
${ }^{2}$ In the years indicated the sectoral shares of agriculture are: $70-27.5-2.8$; industry: $15-29.7-23.3$; services: $15-42.8-74$.

${ }^{3}$ We may add that the choice of the spatial unit of analysis may also be of importance: At what geographic dimensional level does concentration matter? In Tamberi (2002) it is suggested that de-specialization may even occur at the level of industrial district, as a consequence of its economic growth.

${ }^{4}$ As an example, in China, from 1985 to 1998, the $B I$ median - our preferred summary measure of overall specialization - increases from 0.62 to 0.70 at 2 digit level, while it decreases from 0.50 to 0.41 at the 4 digit level (and the linear correlation index between the series is - 0.50); an opposite case is Belgium, where the BI median decreases from 1.05 to 0.89 at two digit disaggregation, but increases from 0.59 to 0.62 at the four digit level (correlation index: -0.70 ).
} 
growth theory has treated economic growth as a pure quantitative expansion of goods (produced through a pure quantitative accumulation of factors) over time; only recently has it been possible to formulate new models in which growth is seen as a process involving the expansion of product variety. Furthermore, it is appropriate to quote Grossman and Helpman (1991) according to whom "Growing economies produce an ever-increasing quantity, quality and variety of goods and services" (p. 334). From this perspective, if we consider the world as a whole, economic growth (consisting in an expansion of product varieties), implies a decreasing degree of overall specialization in the long run. The result is that the second part of a U-shaped pattern fails to appear.

It must also be stressed that the explanation of the relationship between growth and specialization has to be grounded in dynamic trade theories more than in static consideration of international specialization. Reference should be made to Krugman's (1979) North-South model - also developed by Grossman and Helpman (1991) and Sachs (2000) - where the proportion between new and old varieties is fixed in equilibrium, and both North and South will show a continuous expansion of the number of produced varieties at the same rate. That is to say, both regions will develop with a tendency towards ever greater despecialization. ${ }^{5}$

Finally, in growth models of creative destruction the linkages between specialization and growth may have different and more complex dynamics and the possibility of a U-shaped pattern being verified must be taken into account again.

The sign of the relation between trade specialization and growth, its own possible non-linearity, and the possibility of a U-shaped specialization pattern should therefore be revealed by the data.

\section{Empirical evidence on specialization and per capita income}

In this section we describe the data set used herein, the similarities and differences in the measures of specialization; finally, the first descriptive evidence of the linkage between overall specialization and per capita income will be shown. Even though some of the problems highlighted in section 3 cannot be addressed (given that we still work with a fixed number of sectors), we constructed our database - in order to attenuate the limits indicated above -

\footnotetext{
${ }^{5}$ It is necessary to underline that the North level of overall specialization, out of the equilibrium, can depend on the speed of "convergence" (imitation) of the South.
} 
by using a large set of countries, a very large set of sectors and a not overly long time span.

\subsection{Description of the data set}

The data set employed in the empirical analysis stems from two different sources: exports from ECLAC-UN CAN2000 (ECLAC, 2000); per capita income data are from the PENN World Table 5.6 the data of which are available on the World Wide Web in the Global Development Network Growth Database (World Bank, 2002). Specifically:

- export data are based on the SITC rev.2 classification; when not specified otherwise, we work at the four digit level (539 manufacturing ${ }^{6}$ sectors, 786 total sectors);

- the period covered is 14 years, from 1985 to 1998;

- 39 countries were selected on the basis of total GNP PPP 1998 (> 100 as in WB WDI data set).

The choice of total income as a basis for the selection of countries was made to avoid possible distortions due to the presence of too small economies; nevertheless relative per capita incomes range from 7 (Pakistan) to 100 (USA) in 1998;

We chose to work only with the manufacturing sector so as to avoid certain biases that can be induced by the influence of strong specialization linked to geographical and geophysical characteristics: strong advantages in sectors linked to these characteristics would result in algebraic "distortion" of the $B I$ for other sectors (for example e.g. oil exporting countries). We prefer to concentrate our attention on the so called "foot-loose" sectors, because in this case efficiency in exporting is, broadly speaking, due to the same forces leading to economic growth. Nevertheless, we recognize that linkages between primary sectors and manufacturing sectors are not exclusively limited to algebraic questions (as the literature on the Dutch Disease has emphasized).

\subsection{The median of $B I$ as a measure of specialization}

In this section we will build our analysis of specialization on De Benedictis and Tamberi (2002a, 2002b) where it was demonstrated that the median of the sectoral distribution of the $B I$ was a meaningful synthetic indicator of

\footnotetext{
${ }^{6}$ Manufacturing is defined as the sum of sectors from code 5 to 9 , included.
} 
specialization, and that the median itself was related to the level of countries' per capita income.

The Balassa (1965) Index of Revealed Comparative Advantages can be expressed as:

$$
B I_{[c s t \mid w]}=\frac{\frac{X_{c s}}{X_{w s}}}{\frac{X_{c}}{X_{w}}} .
$$

where $X$ are exports, $c$ denotes a specific country, $w$ the world economy, $s$ a specific sector, and $t$ the time period considered. The $B I_{[c s t \mid w]}$ (henceforth $B I$ ) is therefore a sectoral relative export measure in terms of share of world exports. It reveals that country $c$ has a comparative disadvantage in sector $s$ if $0<B I<1$, while it has a comparative advantage in sector $s$ if $1<B I<\frac{X_{w}}{X_{c}}$. Since the Index has a fixed lower bound and a variable upper bound - with a fixed demarcation value in 1 - the $B I$ follows an asymmetric distribution. This makes the median, instead of the mean, the most appropriate indicator of the distribution position.

It is worth noting that the median of the $B I$ distribution, which we will indicate as $m$, is a measure of the number of sectors in which a country shows a revealed comparative advantage: when the median is high it signifies that a country has a comparative advantage in a large share of sectors and it is therefore not specialized; when the median is low, it signifies that a country does not show a comparative advantage in a significant share of sectors, and it is therefore a highly specialized country.

The median is not only a good positional indicator in the presence of skewed distributions, in our case it is also highly correlated to the percentage of sectors with a $B I$ higher than 1 . In our sample of 39 countries the index of rank correlation between $m$ and the percentage of sectors with $B I>1$ amounts to 0.93 , considering all the years from 1985 to 1998 . The above correlation for the pooled data is represented in panel (a) in figure 3 .

Confirmation that the median of the $B I$ is an appropriate measure of specialization comes from the inverse correlation between $m$ and the share of these goods with a $B I>1$ in the total amount of exports of countries, as can be seen in panel (b) figure 3. The coefficient of rank correlation between the two pooled variables is -0.88 . It can be easily demonstrated that this inverse relationship is not just a matter of the algebraic implications of the way the $B I$ is constructed (De Benedictis and Tamberi, 2002a); more relevantly and more important the explanation rests on the fact that rich countries' trade flows are characterized by an intense intra-industry trade.

Furthermore, the $m$ is positively correlated to the level of development, measured by per-capita income, as can be seen in panel (c) figure 3. De- 
spite the considerable dispersion of data, the message of panel (c) appears straightforward: developed countries show a revealed comparative advantage in a larger set of sectors, while poor countries have a comparative advantage in a limited number of sectors and are therefore more specialized, in the sense that they export only a few goods in which the $B I$ is greater than 1 . The rank correlation between the two variables is 0.71 . This evidence also implies that a rich country is a non-specialized one, in the precise sense that its exports are not concentrated in a limited number of sectors.

[Figure 3 about here]

The meaning of figure 3 is quite clear:

1 Developed countries have a comparative advantage in many goods (high median); moreover, they produce with a $B I<1$ over a very wide spectrum of other goods (as indicated by the relative low share in total exports of efficient sectors), due to an intense intra-industry trade: this is due to the fact that these countries also export large quantities of goods for which other countries have a comparative advantage. Developed countries therefore have a low degree of overall specialization.

2 Differently, poor countries export only a few goods where the $B I$ is greater than 1 (a low, sometimes very low median), and they do not export (nearly) anything else (a very high share in total exports of the few sectors with $B I>1$ ). Thus, poor countries have a high degree of overall specialization.

In practice, if we consider both the time and sectoral dimensions, the matrix of export shares is full in the case of rich countries, and largely empty in the case of poor countries. Only some high values in a few cells can be seen for the latter. In short, it is possible to think of $m$ as a very strong inverse indicator of the degree of overall specialization; the median of the $B I$ seems clearly and positively related to development.

We must add that, even if the overall relation between growth and specialization seems to have a negative sign, at least at this descriptive level, many other variables can enter into the explanation of the specialization pattern, both in the long as well as in the short run. The degree of dispersion and the relevance of country specificity are evident in the data. Single countries show different trends, even if most of them confirm the overall positive relation between the two variables at the country level. Exceptions to the general rule are present regardless of the development level of countries. To illustrate this point, we include a multiple plot describing the evolution of 
the $B I$ median of the countries included in the dataset for the period of our analysis (1985-1998).

[Figure 4 about here]

A rapid glance at Figure 4 is sufficient to obtain the impression that single countries have particular trends, independently from the level of per capita income or the initial level of $m$. Since this point is of crucial relevance, we will devote the last section of the paper entirely to clarifying the nexus between country specificity and the overall relation between specialization and growth.

\subsection{The median of $B I$ and alternative measures of overall specialization}

Given that other measures of specialization have been used in the literature, the median of the $B I$ remains an uncommon specialization index. In this section we will therefore briefly compare $m$ to three other proposed indexes of overall specialization: the Gini and Herfindahl indexes, and the so-called Country Gini. ${ }^{7}$ We will compare these four different measures, ${ }^{8}$ applying them to export data. The aforesaid indexes can be divided into two subgroups:

1 Herfindahl and Gini indexes

2 Country Gini and the $B I$ median

In principle, the second sub-group has the relevant characteristics of somehow measuring the relative efficiency of sectors, through the direct comparison of country and world shares in the sectors being considered. Herfindahl and (plain) Gini compare the domestic distribution against a hypothetical and irrealistic equi-distribution. Since our work utilyses trade data, it comes to mind that this feature should be worth consideration. Nevertheless, in practice, all the previous indexes are correlated to each other. Three of them

\footnotetext{
${ }^{7}$ For references on the Country Gini, see Amiti (1998) and Kim (1995). The Index ranges from 0 (when the sectoral distribution in a country is equal to the world distribution) to 1 (when a region has only one sector and this is completely concentrated in that region).

${ }^{8} \mathrm{An}$ alternative to the indexes analyzed in the text could be an entropic index (like the Shannon index), but the use of this kind of index, potentially useful, encounters a strong limit in the presence of logarithms. The latter are not defined when some data are zeros, as in our highly disaggregated data set.
} 
show a much higher correlation; the fourth index (Herfindahl) appears to be different from the others in some respects. The next two tables show the correlation indexes between pairs of concentration measures (using our pooled export data).

Table 1: Correlation between indexes

\begin{tabular}{||l||c|c|c||}
\hline \hline & Country Gini & Herfindahl & BI median \\
\hline Gini & 0,91 & 0.55 & -0.96 \\
Country Gini & & 0.48 & -0.94 \\
Herfindahl & & & -0.42 \\
\hline
\end{tabular}

Table 2: Rank correlation between indexes

\begin{tabular}{||l||c|c|c||}
\hline \hline & Country Gini & Herfindahl & BI median \\
\hline Gini & 0.91 & 0.87 & -0.98 \\
Country Gini & & 0.74 & -0.94 \\
Herfindahl & & & -0.79 \\
\hline
\end{tabular}

Tables 1 and 2 offer an immediate view of the strong correlation between Gini, Country Gini and $m$. The reason for which Herfindahl is less correlated to the others depends on the fact that at our strong disaggregation level export shares are frequently near zero; as a consequence the squares of the export shares are even closer to zero. As a result, this flattens the entire sum of squares to zero, except in a few cases. If Herfindahl is plotted against one of the other three indexes, a non linear relation is evidenced: it is for this reason that rank correlations with this index are relatively higher, as shown in table 2, in comparison with the linear correlations of table 1 . But even in the latter case (rank) correlations between Herfindahl and the other indexes are low when compared with correlations among the components of table 1. In short, using the median of sectoral $B I$ s or one of the two Gini coefficients should not make a large difference; one possible advantage of using $m$ is that it is a synthetic measure of overall specialization derived directly from detailed measures of comparative advantages. Thus, it is possible to move the analysis from a sectoral-specific level to a general one, by making use of the same index. The content of table 3 constitutes an interesting, more complete follow-up of previous themes, as well as an introduction to those in the sections to follow. 
Table 3: Correlation with per capita income

\begin{tabular}{||l||c|c|c|c||}
\hline \hline & Gini & Country Gini & Herfindahl & BI median \\
\hline Simple correlation & -0.67 & -0.74 & -0.29 & 0.70 \\
Rank correlation & -0.66 & -0.74 & -0.48 & 0.71 \\
\hline
\end{tabular}

It is evident that there is cause for reflection, given the positive correlation between the different measures of overall specialization and per capita income. Again, this is true with the exception of the Herfindahl index. As before, we find a weaker relation in the case of the Herfindahl index which becomes relatively stronger in terms of rank correlation.

\section{$5 \quad$ Nonparametric estimates}

\subsection{Kernel smoothing and locally weighted polynomial regressions}

In order to investigate the specialization pattern of different countries we analyse the shape of the relationship between per capita income and the median of the $B I$, which is our preferred measurement of the overall degree of specialization.

The first step forward from the information contained in table 3 is made assuming a linear functional form in the relation between $m$, the median of the $B I$, and per capita income, $y p c$, considering each country $c=1, \ldots, C$ at time $t=1, \ldots, T$.

[Figure 5 about here]

In panel (a) of figure 5 we show the simple linear regression and the associated standard errors derived from the the following functional form

$$
m_{c t}=\alpha+y p c_{c t}^{\prime} \cdot \beta+\varepsilon_{c t}
$$

Even if linearity is the most ubiquitous assumption in applied economics, we will relax it in the present case. The data structure seems to be far richer than the one depicted by a linear relationship. Furthermore, the uneven density in the data, the increase in the standard errors at a high level of per capita income, the variable variance of the residuals, and the significant 
weight of certain observations - identified by Cook's distance - induce us to consider a less stringent functional form. ${ }^{9}$

Instead of choosing a particular non-linear form we opted for a nonparametric estimation of the relation between $m$ and per capita income. The most suitable model, for our purposes, is the following:

$$
m_{c t}=f\left(y p c_{c t}^{\prime}\right)+\varepsilon_{c t}
$$

where $f(y p c)$ is a function of per capita income which is not imposed on the regression a priori. The functional form needs to be estimated according to the general idea that the values of the response variable, $m$, should be averaged locally, under the assumption that the error term $\varepsilon$ is independent with mean 0 and constant variance $\sigma^{2}$. We follow a Kernel smoothing regression procedure (Yatchew 1998; Di Nardo and Tobias, 2001) to allow for a flexible use of the smoothing parameter and to provide the possibility in each local regression of weighting each observation according to its distance from the point of interest.

The use of kernel smoothing techniques offers two main alternatives (Bowman and Azzalini, 1997). The first one is to construct a local mean estimator $^{10}$, implying the following least squares problem:

$$
\min _{\bar{\alpha}}=\sum_{c t=1}^{C T}\left[m_{c t}-\bar{\alpha}\right]^{2} \cdot w\left(y p c_{c t}-y p c ; h\right) .
$$

The second one is to fit a local linear regression, implying the alternative least squares problem:

$$
\min _{\alpha, \beta}=\sum_{c t=1}^{C T}\left[m_{c t}-\alpha-\beta\left(y p c_{c t}-y p c\right)\right]^{2} \cdot w\left(y p c_{c t}-y p c ; h\right) .
$$

In both cases, the kernel function $w\left(y p c_{c t}-y p c ; h\right)$ is in general a positive symmetric function with a maximum at 0 and decreases monotonically as the distance between each observation $y p c_{c t}$ increases with respect to the point of interest, ypc. It follows that more weight is given to the observation close to ypc; the most widely used functions are the triangular, gaussian, and tricube functions. The fixed smoothing parameter $h$ controls the bandwidth

\footnotetext{
${ }^{9}$ The analysis of the linear cases has not been inserted in the paper but are available upon request.

${ }^{10} \mathrm{Imbs}$ and Wacziarg (2000) used this particular class of estimators with a rectangular kernel that gives each observation $y p c_{c t}$ the same weight. The kernel function therefore has a uniform density.
} 
of the kernel function, selecting the number of observations around ypc to be included in the local mean estimation or the local regression.

At this first stage, given the characteristics of our data, as well as our interest in the eventuality of a U-shape and the bias of the local mean estimator at the edges of the covariate space (Fan and Gijbels, 1996), we will use a local linear estimator, with a normal kernel function. Furthermore, the local linear regression has the positive quality of converging to the least squares regression as $h$ becomes larger. Thus a linear regression can be taken as a point of reference.

Indeed, the fitted linear regression displayed in panel (a) of figure 5 is the result of a local linear regression where the smoothing parameter has been fixed at a such high value that all the observations were given approximately the same weight in each local regression.

While the choice of the kernel function is of minor importance, the choice of the smoothing parameter is of first order relevance. As $h$ rises the degree of smoothing of the regression increases, at the risk of missing some nonlinearities in the data; on the other hand, as $h$ falls the risk of overestimating the non-linearity in the data increases. Since the bias of the estimator increases with the size of $h$, while the variance decreases, the choice of $h$ is therefore a matter of compromise. It can be guided by reliable criteria and consistency with researchers' a priori beliefs. Examples of the former are the mean squared error (MISE), which is the sum of the squared bias and variance terms, the cross-validation, which is the minimization of MISE over $h$ (Bowman and Azzalini, 1997) and the iterative analysis of smoothing residuals plots (Cleveland, 1993).

The latter point deserves some further explanation, since it drives our subsequent analysis. Our main a priori belief is that, while the relation between $m$ and $y p c$ may be non-linear, we doubt that it is highly non-linear: this is true for three complementary reasons: (1) the time span considered in the analysis (1985-1998) is reasonably short; (2) the dynamics of specialization is quite a smooth process for every country - under a uniform unit of measure, such as in figure 4 ; (3) the aim of the analysis is to define the relation between $m$ and $y p c$, which is common at a global level; the country data is pooled, and the finding of a highly non-linear relation would be the result of inter-country differences more than a common phenomenon. Our a priori beliefs induce us to choose a reasonably large $h$, resulting in a not overly noisy fit. In choosing $h$ we will follow Cleveland (1993), graphing and smoothing residuals: this involves increasing $h$ to the point where the residual graph just begins to show a pattern and then using a slightly smaller 
value. This procedure is equivalent to a one-sided test ${ }^{11}$ on the size of $h$.

In panel (b) of figure 5 we fitted the data with a local linear regression, a normal kernel function $w(\cdot)$ and a fixed smoothing parameter $h=4500$. Since (Bowman and Azzalini, 1997), $h$ with a gaussian $w(\cdot)$, is the standard deviation of the normal density, the range of observations that contributes to the estimate is $4 h$ in the covariate axis. ${ }^{12}$

The fitted (black) line in panel (b) of figure 5 displays a non-linear relationship between specialization and growth. Countries are more specialized at low levels of per capita income; as $y p c_{c t}$ increases $m$ also increases in a fairly linear way (compare panel (a) and panel (b) in 5): only around $y p c_{c t}=13000 \$$ does some non-linearity become evident. A maximum is reached around $17000 \$$ of per capita income, and for $y p c_{c t}>17000 \$$ the fitted line shows an inversion in the relationship between specialization and growth: rich countries tend to specialize. There is therefore strong evidence that the degree of overall specialization varies along the growth path, following a non-linear dynamic. However the remains surprising to some extent.

Three points must be tackled: (1) the evidence of a U-shaped pattern is dubious. The maximum is reached at a very high $y p c_{c t}$ and the negative sloped portion of the fitted curve is of minor relevance; $(2)$ the linearity of the first portion of the fitted curve can be a sign of overly high $h$; (3) the significance of the fit must be verified through the construction of confidence intervals.

Variability bands can be defined using the estimated mean and variance of $y p c_{c t}$, as was done in panel (a) of figure 5. However, if a bias in the estimate is present, the same bias would be transferred to the reference bands. To avoid this we opted for the bootstrap as an alternative way of generating variability bands. Panel (b) of figure 5 displays the result of 100 resampling, and the area traced by the bootstrap defines a simulated reference band for the regression. While the initial linearity is confirmed, the widening of the band along the right edge of the covariate space reinforces the doubts about the robustness of a U-shaped pattern and its strong dependence on specific observations.

With respect to the value of $h$, the cross-validation criterion suggests the use of the much lower level of $h=700$, and a bandwidth seven times

\footnotetext{
${ }^{11}$ The procedure - not included in this paper but available upon request - can show when $h$ is too large but does not indicates if $h$ is too small. This is a minor problem, given our a priori beliefs, since what we have to check for is excessive smoothness and not the opposite.

${ }^{12}$ For example, if $y p c=10000$ is the point of interest, the linear regression passing through $y p c$ will be estimated considering the observations included in the range 1000-19000, where each observation is weighted according to the distance $y p c_{c t}-y p c$.
} 
smaller than the one used in the regression depicted in panel (b) of figure 5. The analysis of the residuals also indicates that a lower $h$ should be more appropriate. This clashes dramatically with our a priori belief that the relationship between $m$ and $y p c$ was not overly non-linear.

One possible way to reconcile our prior beliefs with the hypothesis of a lower $h$ being a more appropriate choice is to consider the fact that our data are unevenly distributed in the reference space. They feature two clouds of denser observations separated by a region of sparser data and a right edge characterized by a very limited number of observations. In these cases the most advantageous solution is not just to decrease $h$, but to use different smoothing parameters at different covariate values. The fit of our previous nonparametric kernel regression could, in fact, have been influenced by the uneven distribution of the data and by some specific observation. Hence, it would be convenient to use a large $h$ where the data are sparser and the fit appears to be linear, and a smaller $h$ where the data are denser.

One way of doing this (Cleveland, 1993; Bowman and Azzalini, 1997) is to substitute the fixed bandwidth of equation 5 with a variable bandwidth, as in equation 6 ,

$\min _{\alpha, \beta_{1}, \ldots, \beta_{p}}=\sum_{c t=1}^{C T}\left[m_{c t}-\alpha-\beta_{1}\left(y p c_{c t}-y p c\right)-\ldots-\beta_{p}\left(y p c_{c t}-y p c\right)^{p}\right]^{2} \cdot w\left(y p c_{c t}-y p c ; h_{c t}\right)$.

Equation 6 is the least squares problem of a locally weighted polynomial regression (lowess), of $p$-degree, due to Cleveland. The variable bandwidth, $h_{c t}$, reflects the density of the data through the nearest neighbor distance, $d_{k}(y p c)$, which is the distance to the $k$ th nearest neighbor of the covariate value $y p c_{c t}$. The span of the estimator is the parameter $k / C T \in[0,1]$ that describes the proportion of the sample which contributes a positive weight to each local polynomial regression. The smoothness of the regression is therefore dependent on the two parameters $p$ and $k$. Finally, the lowess estimator also incorporates robustness in the fitting procedure, which is appealing in our case where specific observations can exert a significant influence on the fit.

In panel (c) of figure 5 we show the result of an interactive procedure necessary to select $p$ and $k$. The fitted (black) line corresponds to a $p=1$ and $k=0.6 C T$ lowess and is compared with the dotted line that reproduces the kernel estimator of panel (b). The differences between the estimators are not dramatic but remarkable. The smaller bandwidths in the lowess for low $y p c_{c t}$ display an evident non-linearity which was hidden in panel (b). Poor countries slowly decrease their overall specialization; around $y p c_{c t}=7000 \$$ 
the process becomes faster, slowing down again around $y p c_{c t}=13000 \$$ and changing sign at $y p c_{c t}=17000 \$$. As for the local linear regression, the lowess estimator also shows that countries diversify over most of their developmental path, and the evidence on specialization occurring at a mature stage of development is again - in spite of the robustness of the regression - highly dependent on some specific observations. The analysis of the residuals again indicates that a lower $k$ (or a higher $p$ ) should be more appropriate. This suggests the presence of a higher non-linearity in the relationship between $m$ and ypc which can only be reconciled with our a priori belief on the degree of non-linearity of the dynamics if some other covariates different from ypc are influencing $m$. Our choice goes to country specificities.

\subsection{Rolling regressions}

In this section we emphasize the role of the country-specific effect on the relationship between the pattern of specialization and the level of per capita income. Our previous nonparametric regressions implicitly hypothesize that all pairs of $m_{c t}-y p c_{c t}$ are equivalent, regardless of considerations relative to specific country characteristics. In reality, countries differ significantly on many accounts. In particular, measures of overall specialization are likely influenced by the dimension of the economy and its degree of openness, while both geographic position and institutional as well as political considerations may affect countries' per capita income levels. As a consequence, in implementing our nonparametric approach we try to shed some light on the possible role of country-specific effects instead of analyzing the relationships between specialization and growth as if they referred to a single hypothetical country.

We further investigate the relationship between $m$ and $y p c$, implementing a nonparametric procedure carrying out fixed-effects panel rolling regressions. Our procedure consists in running a regression of the dependent variable $m_{c t}$ on the independent variable $y p c_{c t}$ for each subsample of the data, and then plotting the fitted value of the regression evaluated at $y p c_{c t}$. The latter represents the smoothed value used in constructing the nonparametric curve linking $m$ and $y p c$. The above procedure requires the definition of the choice of the bandwidth, that is, the amount of data used in each regression. Our procedure differs from the one previously used, as our scheme involves a fixed number of countries and, therefore, observations in each subsample. In our application we proceed as follows: after sorting the countries into ascending order in terms of the 1985-1998 average per-capita income level, we partition the data of the whole sample into a given number of sub-samples according to overlapping country-intervals of size $z$, with an overlap of size 
$z-1 .{ }^{13}$ In this way, with annual data referring to 39 countries for the period 1985-1998 and a value of $z=5$, we may work with 35 sub-samples, each of which consisting in a fixed number of 5 countries and 70 observations. The countries' average income increases with the sub-samples. Then, we run a simple fixed effects linear regression of the median of the $B I, m_{c t}$, on countries' per-capita income, $y p c_{c t}$, for each subsample using the following model:

$$
m_{c t}=\alpha_{c}+y p c_{c t}^{\prime} \beta+\varepsilon_{c t}
$$

where $c=1,2, \ldots, C$ are cross-sectional countries observed for $t=1,2, \ldots, T$ periods and $\varepsilon_{c t}$ is i.i.d. over individuals and time, with zero mean and variance $\sigma^{2}{ }_{i t}{ }^{14}$ The advantage of such a procedure is twofold: first, we may explicitly take into account country-specific factors in the relationship between specialization and income, as each country is allowed to have its own intercept; and second, we may avoid the problem of estimating the coefficient by measuring the shape of the relationship using regressions characterized by very different degrees of freedom.

According to our nonparametric method we obtain the following values for each of these subsample regressions:

1. a fitted value for the regression, $\hat{m}_{c t}$;

2. a value for the coefficient of the per capita income level, $\hat{\beta}$;

3. and a value for the intercept term for each country $c, \hat{\alpha}_{c}$, which captures the country-specific shifts in the level of sectoral concentration.

[Figure 6 about here]

We report the results of our procedure in figure 6. Panel (a) of figure 6 shows the shape of the curve obtained by plotting the fitted values of the fixed effects rolling regressions evaluated at the average of the related subsample (reported on the $y$-axis) against the average per capita income level of each estimation interval (reported on the $x$-axis). Plotting these fitted values against the average income of the corresponding subsample allows us to

\footnotetext{
${ }^{13}$ The results presented in figure 6 corresponds to a size $z=5$. We tried different values of $z$, but the shape of the relationship was found to be non sensitive to the choice of $z$. Note that $z$ is the analogous of $h$ in the kernel estimations of the previous section. While $z$ is in terms of number of countries included in each local linear regression, $h$ was in terms of intervals - bandwidths - of the covariate.

${ }^{14}$ The fixed effect estimator or within estimator allows the intercept to differ across countries by employing the within-country variation in the data only.
} 
obtain a smoothed curve representing the evolution of specialization throughout the developmental path. It suggests a non-linear relationship between the overall degree of specialization and per capita income levels ${ }^{15}$ where the shift towards re-concentration, represented by the downward-sloping portion of the curve, seems to occur late in the developmental process. However, to assess the statistical significance of the prominent role of income in explaining sectoral diversification compared to to country-specific effects such as size, openness, ecc., we have to take into account both sources of changes in the fitted values of $m$.

In what follows we deepen our consideration of this question by analyzing the way the values of the slope term of income and of the (average) intercept term change along the subsamples. Panel (b) of figure 6 shows the shape of the curve obtained by plotting the estimated slope term of the per capita income obtained in the fixed effects rolling regressions (reported on the $y$-axis) against the average per capita income level of each estimation interval (reported on the $x$-axis). It confirms the non-linear relationship exisitng between specialization and per capita income, with the values of the $\beta$ coefficients lowering as the per capita income increases. Panel (c) of figure 6 shows the shape of the curve obtained plotting the estimated average intercept term obtained in the fixed effects rolling regressions (reported on the $y$-axis) against the average per capita income level of each estimation interval (reported on the $x$-axis). As before, the relationship is non-linear along the subsamples, with the values of the intercept terms being close to zero in the beginning, getting higher as income grows, and decreasing in the final subsamples. The analysis of the changes in the estimated slope term of the per capita income and average intercept term represented in panel (b) and (c ) of figure 6 suggests a potentially interesting interpretation of the nonlinearity in the relationships between sectoral concentration and per-capita income. In particular, ypc seems to above all affect the pattern of $m$ at the left edge of the covariate space, while $\hat{\alpha}_{c}$ seems to be more relevant than $y p c$ in explaining countries' sectoral diversification at the right edge of the covariate space.

\section{Conclusions}

Let us summarize only the main steps of our analysis. Initially we discussed the meaning and the empirical aspects of the concept of overall specializa-

\footnotetext{
${ }^{15}$ This non-linear relationship is confirmed whatever the measure of specialization employed is (i.e. Gini, Country Gini and Herfindahl indices). The results and figure relative to the other measures of specialization may be obtained upon request to the authors.
} 
tion; we then revised and compared different measures for it; finally we tried to clarify the kind of relationship that seems to exist between growth and specialization.

Our results seem to be consistent with the lessons deriving from both old and new theories on growth and development. Indeed, the finding of a non-linear relationship between specialization and income may be the result of the prevailing influence that the level of per-capita income, on one hand, and, on the other hand the country-specific effects may have on sectoral diversification according to the stage of development of a country. In this way the evolution of the specialization pattern in relation to the level of percapita income may be the result of the interaction of countries' per-capita income and other country-specific variables captured by the intercept of the fixed-effect regression. The level of per capita income seems to above all affect the pattern of specialization in the early stages of development, while the average intercept term, and therefore the country-specific effects, seem to be more important than income in explaining countries' sectoral specialization in the medium and late stages of development. 


\title{
Appendix A: List of countries, ordered accord- ing to 1985-1998 average per capita income:
}

\author{
INDIA \\ PAKISTAN \\ BANGLADESH \\ CHINA \\ PHILIPPINES \\ EGYPT \\ INDONESIA \\ ALGERIA \\ SOUTH AFRICA \\ COLOMBIA \\ TURKEY \\ THAILAND \\ BRAZIL \\ POLAND \\ CHILE \\ MALAYSIA \\ ARGENTINA \\ MEXICO \\ VENEZUELA \\ GREECE \\ PORTUGAL \\ KOREA \\ SPAIN \\ ISRAEL \\ ITALY \\ AUSTRIA \\ FINLAND \\ BELGIUM \\ UK \\ NETHERLAND \\ FRANCE \\ SWEDEN \\ JAPAN \\ DENMARK \\ AUSTRALIA \\ SWITZERLAND \\ NORWAY \\ CANADA \\ USA
}




\section{References}

Amiti M. (1998), New Trade Theories and Industrial Location in the EU: A Survey of Evidence, Oxford Economic Policy, vol 14, n. 3, 45-53.

Balassa B. (1965), "Trade Liberalization and Revealed Comparative Advantages", Manchester School of Economics and Social Studies, 33, 99123.

Bensidoun I., Guillaume G., and Unal-Kesenci D. (2001), "The Nature of Specialization Matters for Growth: an Empirical Investigation", CEPII WP, 13, December.

Bowman A. W. and Azzalini A. (1997), Applied Smoothing Techniques for Data Analysis, Clarendon Press, Oxford.

Brasili A., Epifani P., and Helg R. (2000) "On the Dynamics of Trade Patterns",De Economist, 148(2), 233-258.

Brülhart M. (1999), "Growing Alike or Growing Apart? Industrial Specialization of the EU Countries", in C. Wyplosz (ed.) EMU and its Impact on Europe and Developing Countries, Oxford, Oxford University Press.

Cleveland W. S. (1993), Visualizing Data, Hobart Press, Summit, New Jersey.

Deardorff A. (1974) "Factor Proportions and Comparative Advantage in the Long-run: Comment", Journal of Political Economy, 82(4), 829-833.

De Benedictis L. and Tamberi M. (2002a), A Note on the Balassa Index of Revealed Comparative Advantage, Quaderni di ricerca n. 158, Dipartimento di Economia, Università di Ancona, Gennaio (http://www.dea.unian.it /quaderni/pdf/158.pdf).

De Benedictis L. and Tamberi M. (2002b), Il modello di specializzazione italiano: normalità e asimmetria, Quaderni di ricerca n. 160, Dipartimento di Economia, Università di Ancona, Febbraio (http://www.dea.unian.it /quaderni/pdf/160.pdf).

DiNardo J. and Tobias J. L. (2001), "Nonparametric Density and Regression Estimation", Journal of Economic Perspectives, 15(4), 11-28.

Dixit A. and Norman V. (1980), Theory of International Trade, Cambridge, Cambridge University Press.

Eaton J. (1987) "A Dynamic Specific-Factors Model of International Trade", Review of Economic Studies, 2, April, 325-338.

ECLAC (2000), CAN2000, Economic Commission for Latin America and the Caribbean.

Fan J. and Gijbels I. (1996), Local Polynomial Modelling and Its Applications, Chapman and Hall, London.

Findlay R. (1970), "Factor Proportions and Comparative Advantage in the Long Run", Journal of Political Economy, 78(1), 27-34. 
Grossman G. M. and Helpman E. (1991), Innovation and Growth in the Global Economy, the MIT Press.

Imbs J. and Wacziarg R. (2000), "Stages of Diversification", CEPR Discussion Papers, 2642, December.

Kim S. (1995), "Expansion of Market and the Geographic Distribution of Economic Activities: the Trends in U.S. Regional Manufacturing Structure, 1860-1987", The Quarterly Journal of Economics, November, 881-908.

Krugman P. (1979), "A Model of Innovation, Technology Transfer, and World Income Distribution", Journal of Political Economy, 2, 253-266.

Krugman P. (1980), "Scale Economies, Product Differentiation, and the Pattern of Trade", American Economic Review, December, 950-959.

Krugman P. and Helpman E. (1985), Market Structure and Foreign Trade, Cambridge, MIT University Press.

Kuznets S. (1973), "Modern Economic Growth: Findings and Reflections", American Economic Review, n.5, 247-258.

Lucas R. (1988), "On the Mechanics of Economic Development", Journal of Economic Development, 22, 3-42.

Maddison A. (1995), Monitoring the World Economy 1820-1992, OECD.

Proudman J. and Redding S. (2000), "Evolving Patterns of International Trade", Review of International Economics, 8(3), 373-396

Redding S. (2001), "The Dynamics of International Specialization", CEPR discussion papers, 2287, May.

Sachs J. (2000), "Globalization and Patterns of Economic Development", Welwirtschaftliches Archiv, 4, 579-600.

Schott P. K. (2001), "Do Rich and Poor Countries Specialize in a Different Mix of Goods? Evidence from Product Level US Trade Data", NBER working paper, n. 8492, September.

Tamberi M. (2002), "Trasformazioni produttive nei sitemi locali delle Marche", in Becattini G., Bellandi M., Dei Ottati G., Sforzi F. (eds) Il caleidoscopio dello sviluppo locale, Torino, Rosenberg \& Sellier.

Yatchew A. (1998), "Nonparametric Regression Techniques in Economics", Journal of Economic Literature, June, 36(2), 135-143.

Young A. (1991), "Learning-by-doing and the Dynamic Effects of International trade", Quarterly Journal of Economics, 106, 396-406.

Weinhold D. and Rauch J.E. (1999) Openness, Specialization, and Productivity Growth in Less Developed Countries, Canadian Journal of Economics, Vol. 32 (August): 1009-1027.

World Bank (2002) Global Development Network Growth Database, World Bank, http://www.worldbank.org/research/growth/GDNdata.htm. 
Figure 1: Specialization

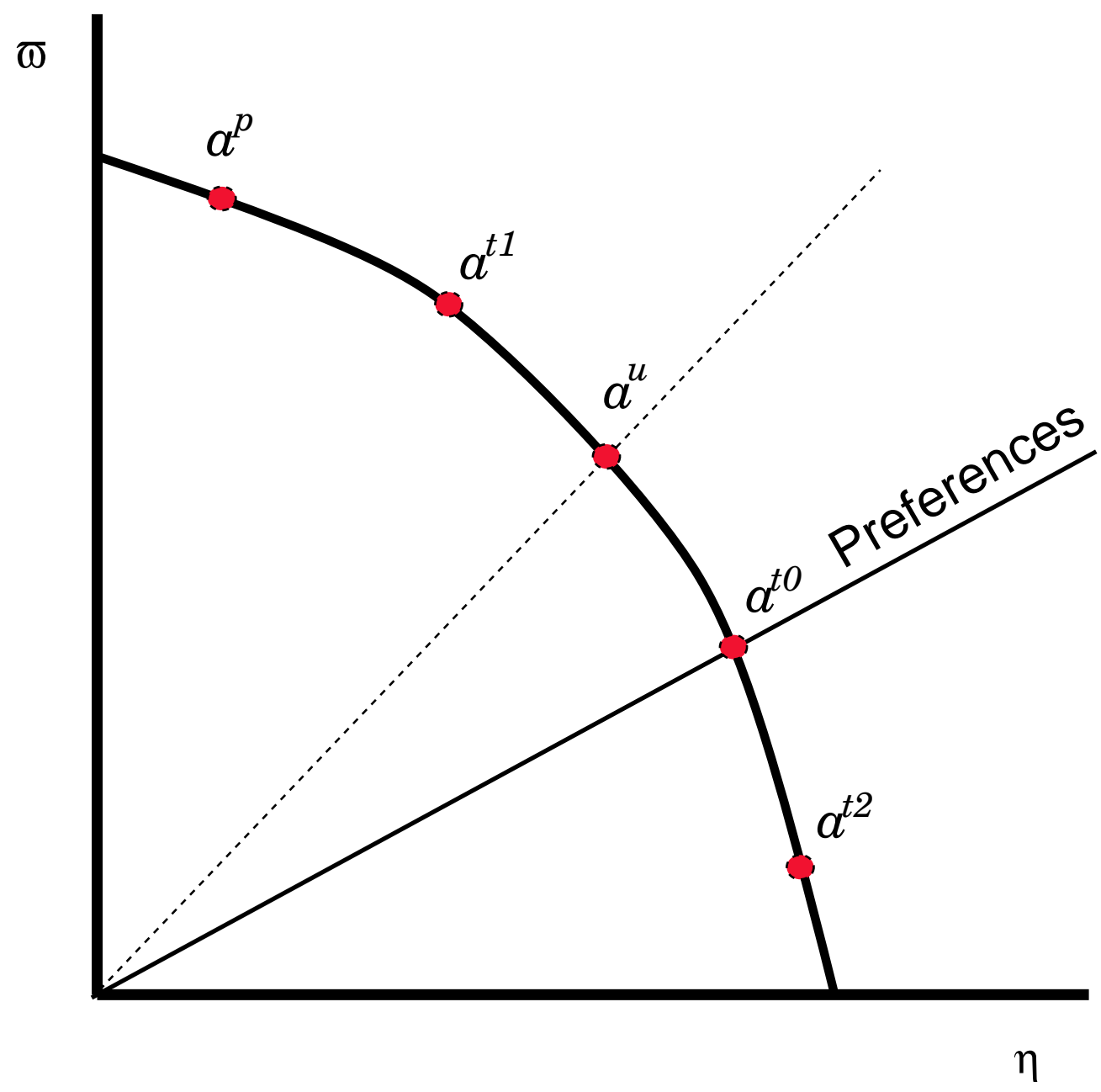


Figure 2: Findlay-Schott's graph

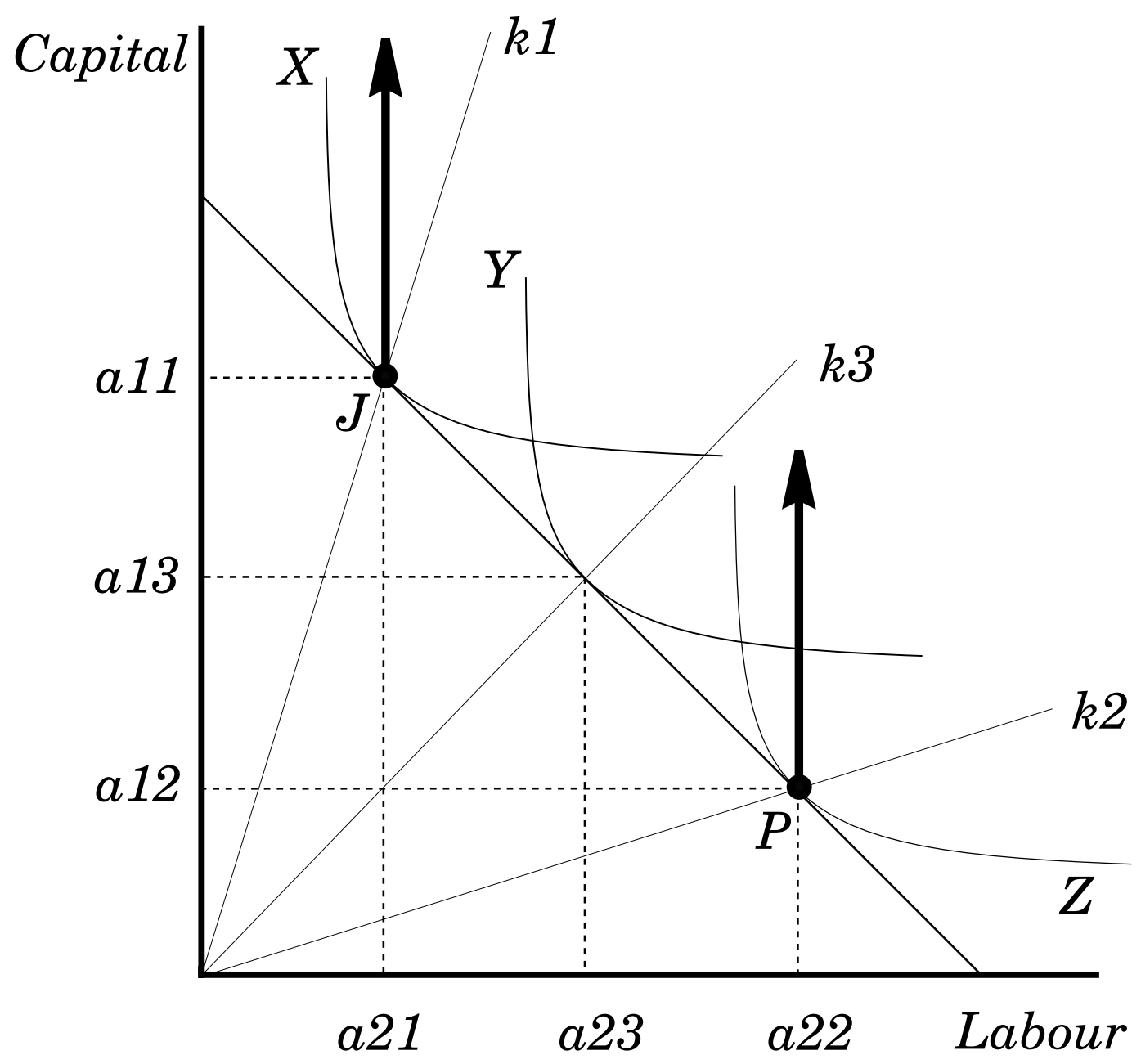


Figure 3: Specialization and Growth - pooled data 1985-1998

(a)

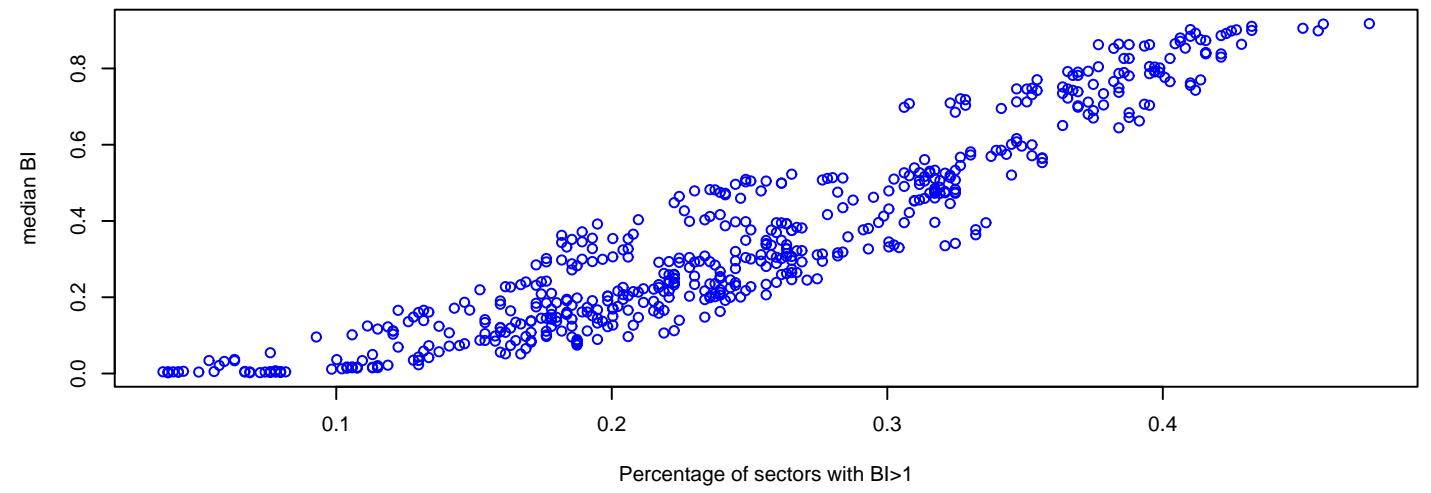

(b)

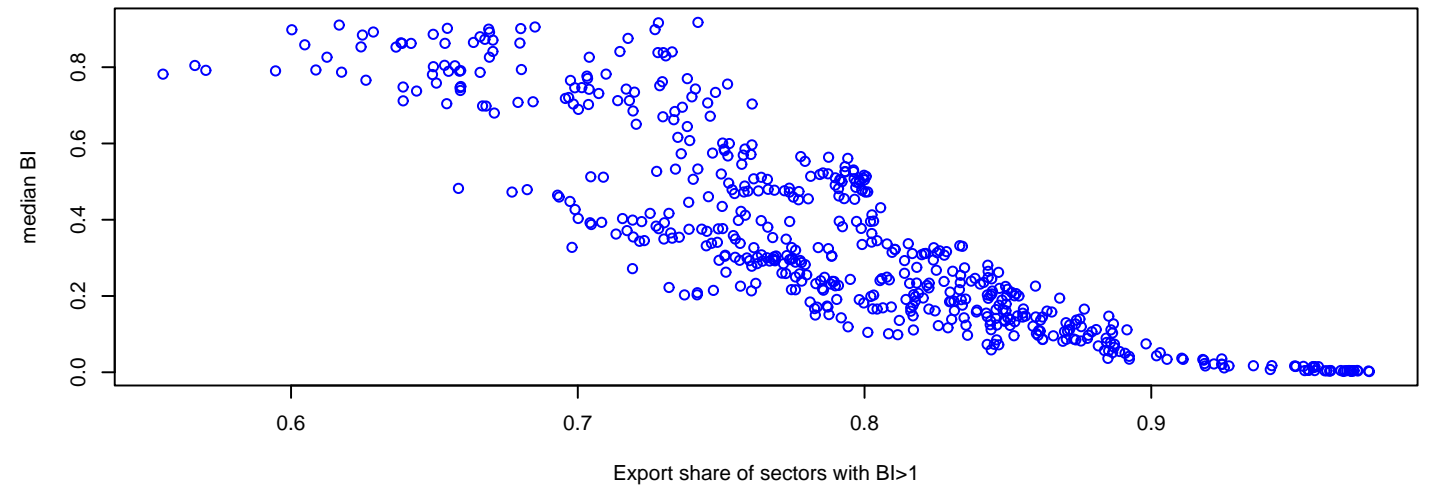

(c)

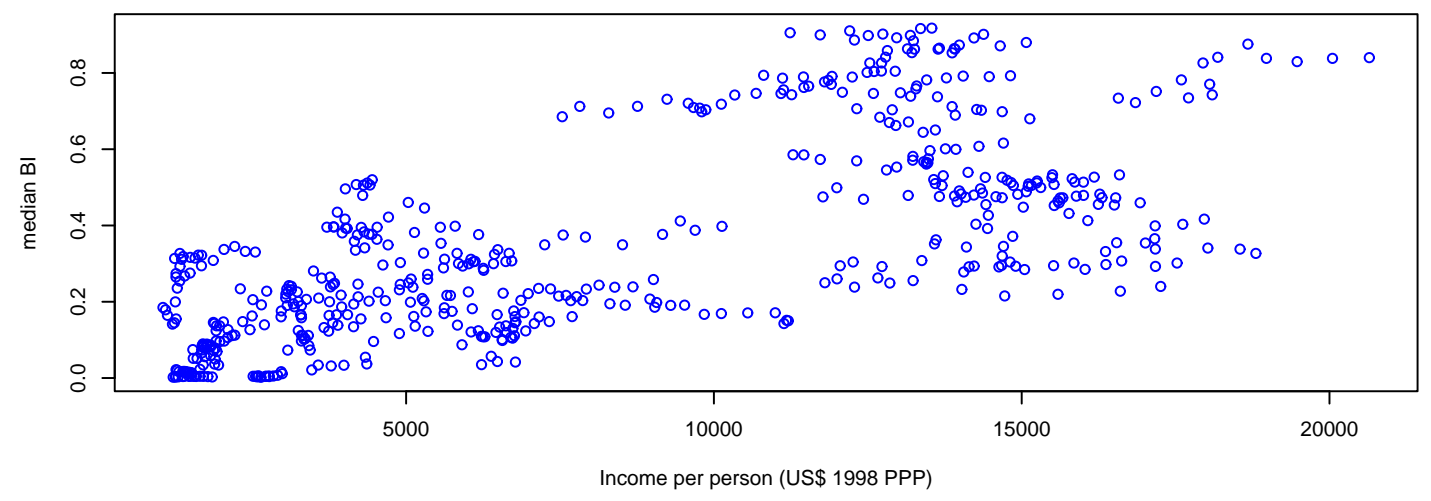


Figure 4: $m$ - The 39 countries in the database

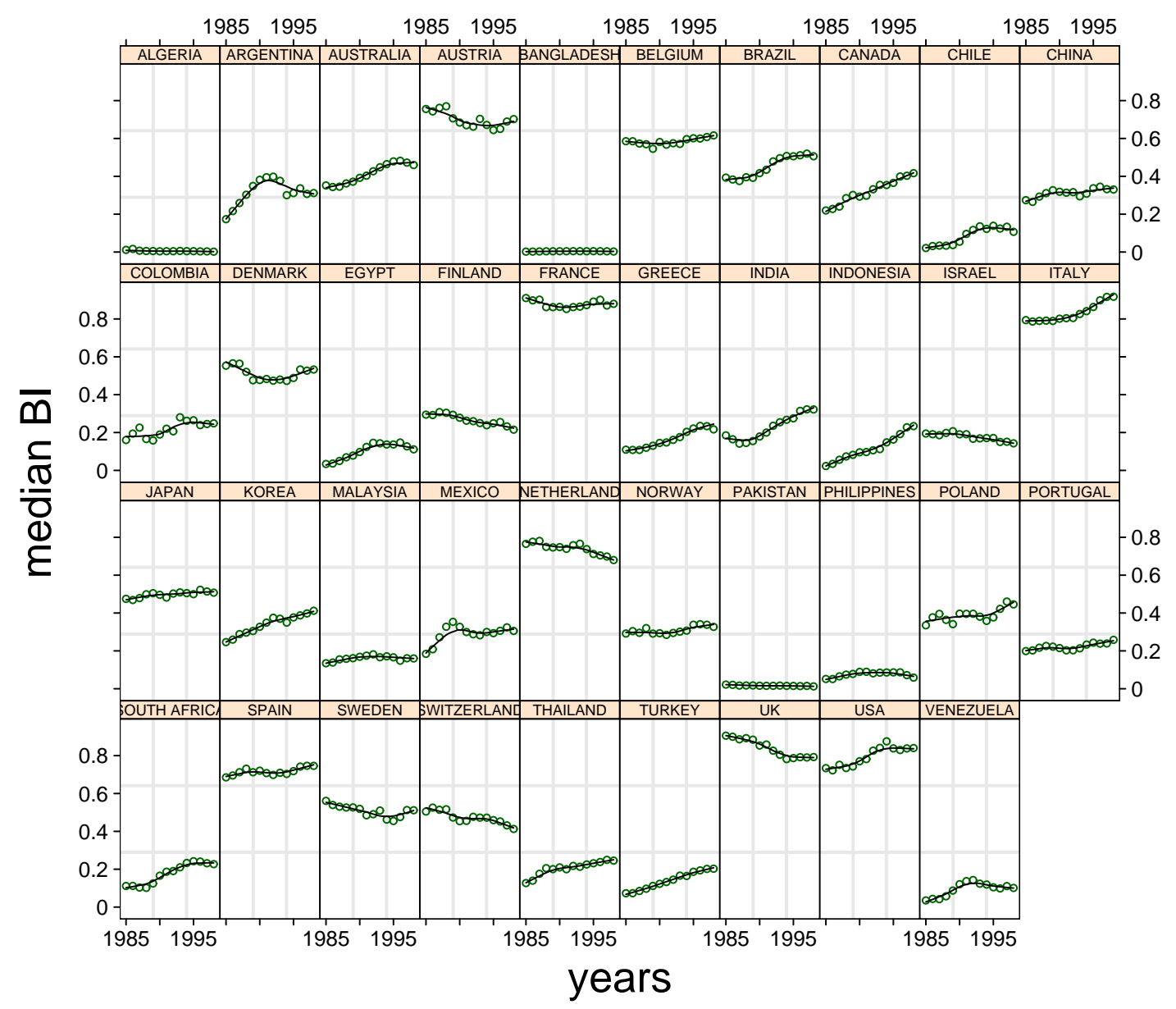


Figure 5: Nonparametric Regressions

(a)

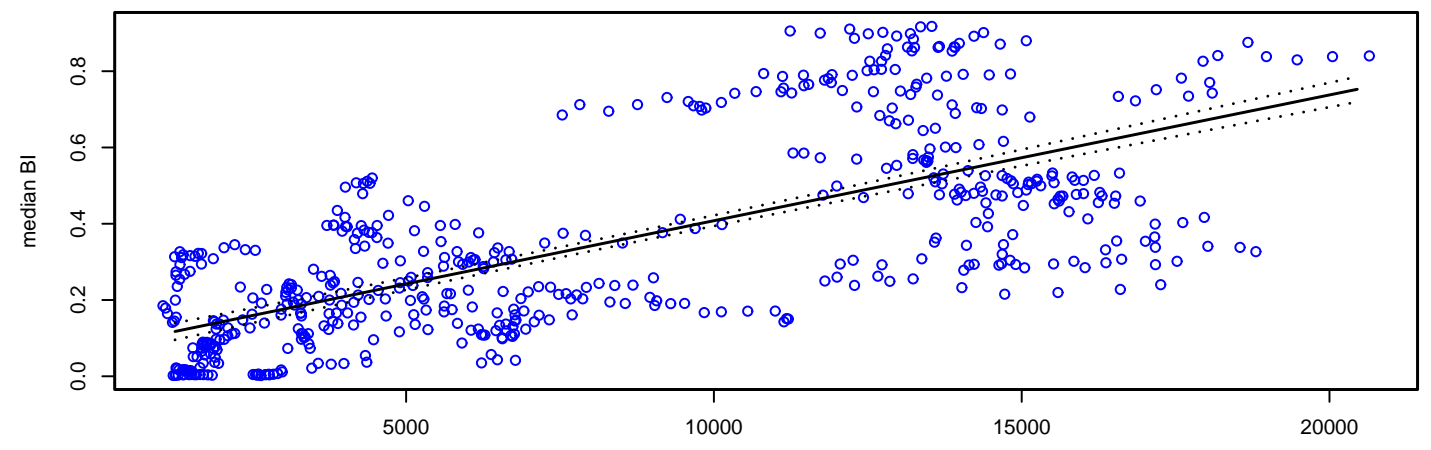

(b)

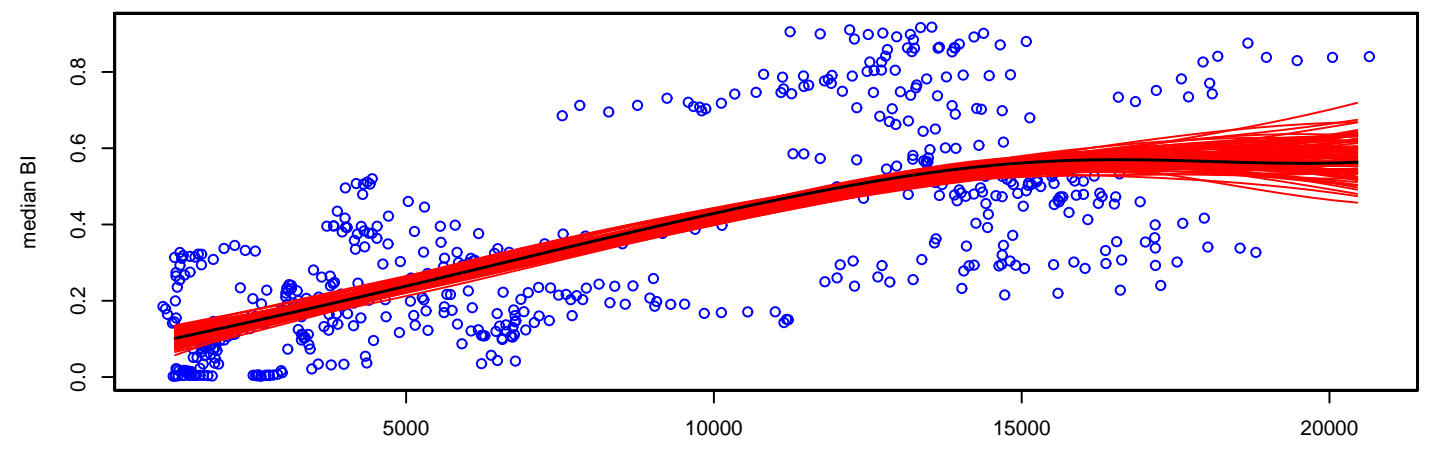

(c)

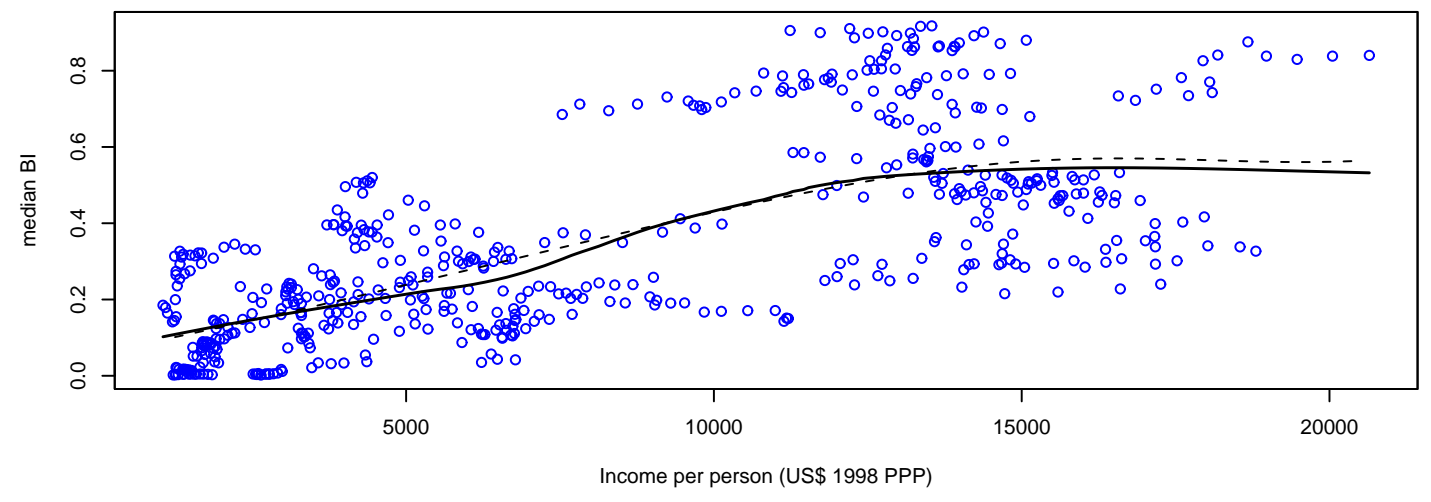


Figure 6: Rolling regression

(a)

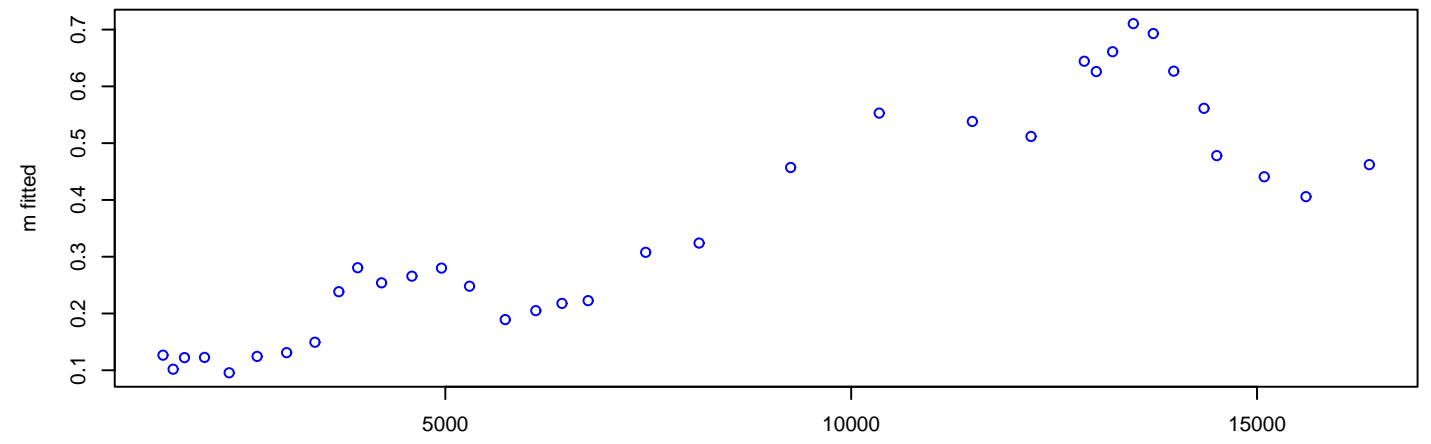

(b)

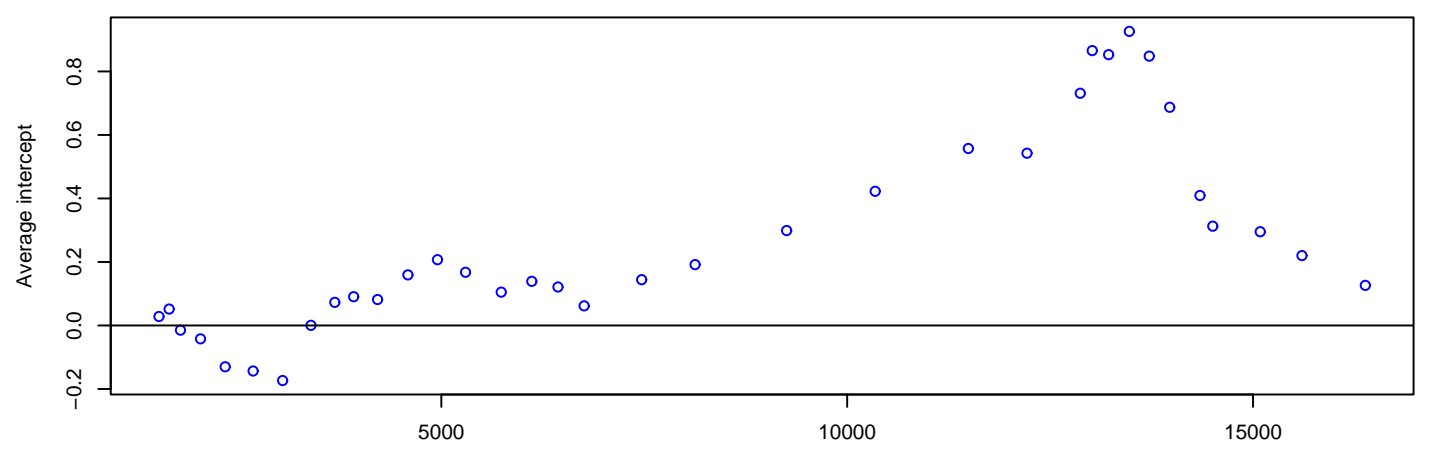

(c)

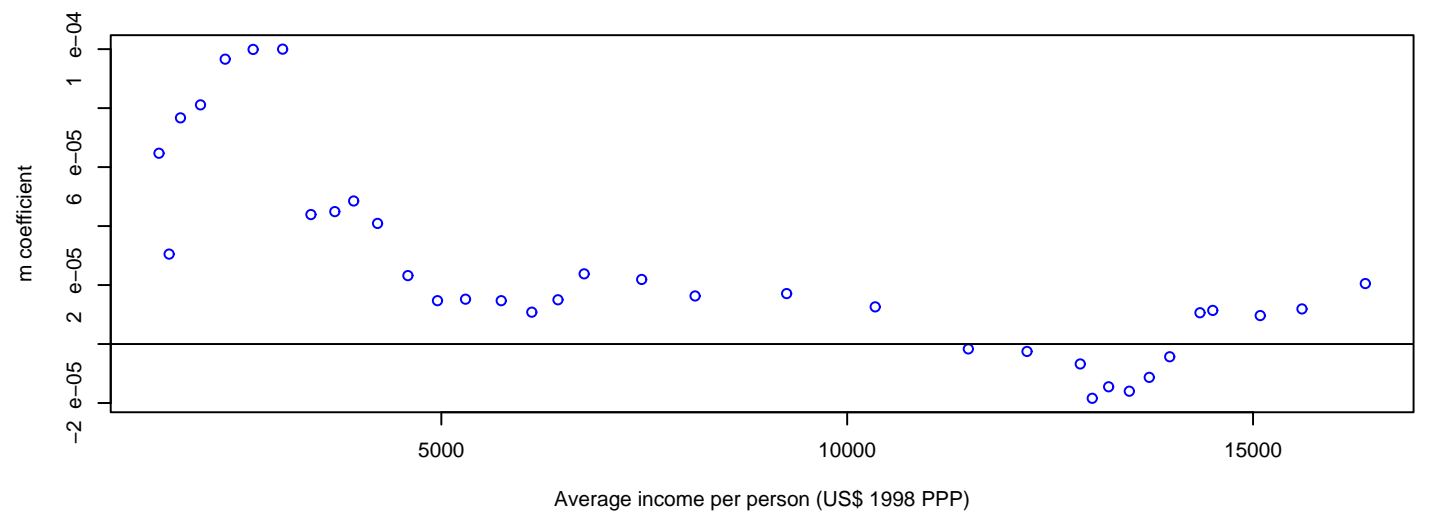

